\title{
Community Service-Learning in a Large Introductory Sociology Course: Reflections on the Instructional Experience
}

\author{
Jana Grekul, Wendy Aujla, Greg Eklics, Terra Manca, Ashley Elaine York, \\ and Laura Aylsworth
}

\begin{abstract}
AвSTRACT This paper reports on a pilot project that involved the incorporation of Community Service-Learning (CSL) into a large Introductory Sociology class by drawing on the critical reflections of the six graduate student instructors and the primary instructor who taught the course. Graduate student instructors individually facilitated weekly seminars for about 30 undergraduate students, half of which participated in CSL, completing 20 hours of volunteer work with a local non-profit community organization. We discuss the benefits of incorporating CSL into a large Introductory Sociology class and speculate on the value of our particular course format for the professional development of graduate student instructors. A main finding was the critical importance to graduate students of formal and informal training and collaboration prior to and during the delivery of the course. Graduate students found useful exposure to CSL as pedagogical theory and practice, and appreciated the hands-on teaching experience. Challenges with this course structure include the difficulty of seamlessly incorporating CSL student experiences into the class, dealing with the "CSL" / "non CSL" student division, and the nature of some of the CSL placements. We conclude by discussing possible methods for dealing with these challenges.
\end{abstract}

KEYWorDs graduate student training, community service-learning

Graduate students are frequently encouraged and expected to gain teaching experience early in their academic careers. Often these early experiences take the form of a graduate student teaching assistantship. In some cases, these assistantships are graduate students' only teachingrelated training and often occur within the context of large introductory classes. Primary instructors who teach these large introductory courses are faced with two challenges: educating undergraduate students and also providing an opportunity for pedagogical training of their graduate student teaching assistants. Unfortunately, the prevalence of large classrooms in many universities limits primary instructors' ability to adopt pedagogies that avoid privileging the classroom as the only site of (and for) learning. Indeed, the use of community servicelearning (CSL) in introductory sociology courses is nearly non-existent because of difficulties implementing CSL with existing resources, relative lack of CSL knowledge and experience, and the time and effort it requires from instructors (Hondagneu-Sotelo \& Raskoff, 1994, p. 253). 
This paper explores our attempt to directly challenge these issues. We approached the course as a team, led by Jana, a sociology professor who was the primary instructor for the course, and six graduate student instructors, all of whom were sociology doctoral students at the time of the course. None of the graduate student instructors had previously engaged with community service-learning as an instructor. Some of the graduate student instructors had previously led seminar groups/tutorials. We had two primary objectives for the course. First, through the incorporation of community service-learning, we aimed to meaningfully engage undergraduate students with the course material, instructors, and community. Second, graduate student instructors were provided with the opportunity to teach hands-on and to actively facilitate the incorporation of CSL in the course. Each graduate student led a seminar group of about thirty students. ${ }^{1}$ While this experience included many challenges, it provided the primary instructor and graduate student instructors with valuable teaching and learning experience. We also encountered various difficulties that are inherent in developing a class that balances specific course objectives with the diverse interests, objectives, and skills of multiple graduate student instructors, community partners, CSL staff, and the primary instructor. Our experiences offer an example for others exploring alternate teaching and learning strategies, and/or navigating multiple graduate student instructors and community partners in large classrooms. In an era of increased university enrolments and reduced budgets, experiences such as these are, arguably, valuable for the quality of undergraduate education and graduate student training.

This paper focuses primarily on the impacts that incorporating CSL in large undergraduate classrooms can have on graduate student instructors. Following a description of the background for and the design and implementation of the course, we reflect on graduate student instructors' experiences engaging CSL as pedagogical practice for the first time, including some of the benefits and challenges of incorporating CSL into the course. Then, we speculate on the professional development value of this course format for graduate student instructors - a topic that lacks sufficient research and resources (Gardner \& Jones, 2011; Hou, 2010; Lena, 1995; O’Meara \& Niehaus, 2009; Pribbenow, 2005). We highlight the ways that our class format bridged graduate student instructors' formal and informal mechanisms of support and discuss how graduate student instructors develop professionally from exposure to transformative pedagogies like CSL, which offer powerful teaching tools to engage students with course content.

\section{Background}

The University of Alberta is a large public Canadian university located in Edmonton, Alberta. The Introductory Sociology course is required for Sociology majors, but attracts students from various faculties including Science, Business, and Education because it fulfills a social sciences degree requirement for these faculties and disciplines. The introductory classroom is an ideal space for maximizing student exposure to the sociological perspective because it

\footnotetext{
${ }^{1}$ The entire class attended lectures provided by the primary instructor twice a week (Monday and Wednesday) and then met
} with their respective graduate student instructor-led seminar groups every Friday.

Engaged Scholar Journal: Community-Engaged Research, Teaching, and Learning 
attracts diverse students (i.e. first- to fifth-year, urban and rural, ethnically/culturally diverse, and international students). The course's primary objective is to encourage students to begin to look at social issues differently_sociologically_and develop critical sociological thinking skills.

CSL would seem naturally to complement this course, which covers such topics as "racial and ethnic stratification," "gender inequality," "crime and deviance," and "stratification by class." Ideally, undergraduate students explore the concepts learned in the classroom through hands-on CSL projects outside the classroom. They bring their community experiences back into the classroom to share, thereby creating the potential for critical thinking and transformative learning. This type of learning challenges "taken-for-granted frames of reference" and provides students an opportunity for reflection and change and "new understanding $[\mathrm{s}]$ of the social world" (Jakubowski \& Burman 2004, p. 162; Chesler, Ford, Galura, \& Charbeneau, 2006; Mezirow, 2000, p.7; McGonigal, 2005; Miller \& Groccia, 1997; Potter, Caffrey, \& Plante, 2003).

There is a trend among some sociologists to ground their discipline and teachings "in the real world," a world to which students can relate. For some, sociology is moving toward a more applied and practical discipline (Brooks, 1997); the use of practica, internships, and co-ops helps move sociology classes and programs in the direction of experiential learning, encouraging students to embrace these opportunities to "do sociology" (Mooney \& Edwards, 2001, p. 183). CSL provides students a unique opportunity to bridge what is often perceived as a community-classroom divide. According to Lena (1995), "[CSL] permits students to test their insights about sociological phenomena in the field and to reflect on their real-life experiences in a more academically rigorous way" (p. 109-110). Without such experiential learning practices, it is less likely that students will "develop sentiments of obligation, commitment and responsibility toward their future communities, and less likely that they will realize their own potential roles in ameliorating social problems" (Hironimus-Wendt \& Wallace, 2009, p. 83).

\section{Planning, Design, and Implementation of the Project}

\section{Planning}

The course was a special section of introductory sociology (a 3-credit course), with six graduate student instructors, taught during the 2011 fall term. To prepare for this unique course offering with six seminar sections, the CSL program on campus provided crucial support to the instructors (primary and graduate student) during the summer months leading up to the course. Two of the graduate student instructors had experience in facilitating seminars with previous introductory sociology courses offered by the department. The new challenge was the incorporation of CSL into the seminars. The primary instructor had experience teaching the course with and without graduate student instructors and also had experience incorporating CSL into upper level sociology courses with fewer students. She believed graduate student instructors could benefit from the teaching experience of running their own weekly seminar groups, as well as from an exposure to CSL pedagogy. Three of the graduate student instructors had been exposed to CSL as students, but overall the graduate student instructors had little 
previous knowledge of or experience with CSL. They were, however, eager to learn about it and explore its potential as a pedagogical approach.

A number of challenges accompany any effort to incorporate CSL into a course (Butin, 2007), but limited research has examined these challenges in practice (Hou, 2010). In our case, the enrollment of 180 students (over $70 \%$ of whom were first- or second-year students) provided an additional challenge. We quickly learned that "large class sizes require logistical and administrative oversight that is likely to only grow when service learning is added to the mix" (Hill, Loney, \& Reid, 2010, p. 398). Furthermore, "this requires a significant degree of faculty commitment to service learning. These challenges combine to make service learning within large undergraduate classes seemingly rare" (Hill, Loney, \& Reid, 2010, p. 398). The size of the class made our attempt unique from other courses with CSL in our institution.

Without a doubt, the involvement of the CSL program on our campus was integral to the execution of this project. CSL started as a pilot project at the University of Alberta in 2003 with three sociology courses, eight community partners, and 40 students. $^{2}$ By 2015, it was an established program facilitating partnerships between more than 75 courses and 180 community partners, providing community-based opportunities for over 1500 students. As its mission, the CSL program is committed to fostering "reciprocal relationships between $\mathrm{U}$ of A instructors and community partners that create opportunities for students to reflect on and explore classroom and community learning" ("Mission, Vision, Values," n.d.). Essentially, the CSL program and staff act as liaisons and consultants for instructors interested in incorporating CSL into their courses: they provide the instructors with resources on the pedagogy behind CSL, recruit community partners, set up the student placements, and provide support throughout the term for instructors and students.

In consultation with the primary instructor, the CSL program arranged the community partnerships that suited the course topics, assisted in the introduction of graduate student instructors to their respective community partners, provided training and support in the weeks leading up to the course, and then offered support throughout the course. This training and support took several different forms and went above and beyond what the CSL program typically does for a CSL course on campus. CSL staff were invested in the experimental nature of this project and provided in-kind support to the project through additional training and support.

CSL staff assisted with the course design and met with the primary instructor and graduate student instructors approximately four times in the weeks leading up to the start of the term. Also during this time, multiple resources including three CSL-related articles (Butin, 2007; Himley, 2004; Westheimer \& Kahne, 2004) were shared with the graduate student instructors to ensure they understood what their appointment entailed and how it would be different from previous teaching assistantships. The CSL program also has a handbook for all instructors using CSL, which was provided to the course instructors prior to the meetings. In additional

\footnotetext{
${ }^{2}$ Following the pilot, in 2005 the CSL program on our campus along with staff, dedicated resources, and on-going funding was created. For more information, see the program website: www.ualberta.ca/community-service-learning.
} 
meetings, the CSL Partnership Coordinator outlined procedures and strategies for graduate student instructors to use in working with their respective community partners, including administrative processes and deadlines.

In addition to this support, graduate student instructors also attended a half-day orientation offered by the CSL program to all instructors and community partners embarking on a CSL course. This session provides participants with an overview of CSL, its philosophy, and a discussion of its benefits and challenges as well as the practical and administrative components of the process. In the orientation, CSL staff also highlight responsibilities, such as the graduate student instructors' role in facilitating discussions with community partners about the logistics of the partnership. Orientation also provides an opportunity for graduate student instructors and the primary instructor to hear from other instructors who are incorporating CSL, some for the first time and others returning to it as a pedagogical tool.

Designing and implementing effective CSL courses requires extensive time, energy, and knowledge (Butin, 2007, p. 35). In preparation for the course, graduate student instructors and the primary instructor met regularly to arrange the standardized weekly seminar topics and co-design written assignments. Outside of CSL support, several steps were taken to train the graduate student instructors so they could effectively facilitate weekly seminars and evaluate students' written work. In one session, the primary instructor shared several seminar exercises that were used in the past by graduate student seminar instructors. The group discussed ways of implementing the exercises and tactics for facilitating discussions and debriefs following the activities. In another training session, a writing and teaching expert from the campus Centre for Writers facilitated a two-hour session for the group, presenting a step-by-step process for creating possible writing assignments for students in the seminars. Part of this training also involved lessons and practice in creating effective marking rubrics for the assignments. Graduate student instructors worked together on producing assignments and shared marking rubrics, which helped with providing meaningful and consistent feedback to students. An additional session, led by the primary instructor, was devoted to the creation of the seminar syllabus (separate from the course syllabus). Each graduate student instructor was given some degree of freedom to create a seminar syllabus that reflected his/her individuality while still maintaining standardization with the rest of the team (i.e., weighting of assignments was standard across seminars, but exercises and expectations for seminar participation marks varied). Prior to the commencement of the course, each graduate student instructor created his/her own seminar syllabus, lectures, discussion questions, exercises, and means of tracking seminar participation.

The team continued to meet throughout the course, meeting weekly for the first half of the term and then bi-weekly to discuss seminar activities and experiences with the integration of CSL in the course and, especially, to support each other in this journey.

\section{Design}

Prior to the assignment of graduate student instructors to the course, the primary instructor and CSL staff decided that for this first attempt at integrating CSL into such a large classroom, the 
six graduate student instructors would each partner with one community agency and facilitate a corresponding seminar section. Although this restricted graduate student instructor input into the format of the course, administrative deadlines and bureaucratic processes rendered it the only feasible option. Accordingly, each graduate student instructor was responsible for a seminar group of about thirty students (half of whom were doing CSL) that would meet weekly and was involved with one agency. For example, one graduate student instructor worked with Habitat for Humanity: her CSL students helped build a house. Another graduate student instructor partnered with the local John Howard Society branch and his CSL students participated in a carnival event for inner city families. Graduate student instructors were asked to email the primary instructor their first and second choice of community partners (out of a total of six community partners). Fortuitously, each graduate student instructor was able to partner with their community partner of choice.

One of the logistical challenges we worked on over the summer was how to provide a meaningful learning opportunity for all students, given that there were only a limited number of CSL spots available. Due to a variety of reasons (space, staff responsibilities, etc.), each community partner was only able to take a maximum of 15 students. This meant that only half $(n=90)$ of the students registered in the course could participate in the CSL option. The other students required an equally meaningful assignment to enhance their learning and contribute to seminar discussions. We decided that the remaining 90 students would participate in media analyses, critically reading and analyzing newspaper articles related to a specific social issue such as homelessness, poverty, social status, and domestic violence. Students would select three or more reputable newspapers (e.g. The Edmonton Journal, The Globe and Mail, The Guardian, The National Post, The New York Times) to follow throughout the term and analyze articles about their chosen topic. Similar to the CSL students, the media students would bring their experiences reading articles on their chosen topic into the seminar discussions. For example, media students in the seminar group that partnered with the Elizabeth Fry Society Court Work Program would be encouraged to research topics related to women's victimization, domestic violence, prostitution, and the gendered nature of crime and criminal justice.

Optional CSL placements for a proportion of the class are typical at our institution, and the CSL program offers advice and assistance to instructors as they strive to create equality between CSL and "non-CSL" student coursework. In our course, CSL students were required to complete twenty hours of work with their community agency. They were also required to complete two reflective journals based on their placement experiences. In an attempt to equalize the work load between CSL and media students, media students were required to complete three reflective journal assignments based on their media analysis. These assignments asked students to take one of their articles and write a one to two page sociological analysis on it. We estimated that these assignments, combined with the ongoing media analysis, would be a comparative workload to that carried by the CSL students.

\section{Implementation}

All of the community partners, the Partnership Coordinator from the CSL program, and the 
six graduate student instructors were invited to attend the first class of the term. The staff member from the CSL program explained the basics of CSL participation to students; each community partner gave a brief overview of their organization and placement responsibilities/ projects. Graduate student instructors then introduced themselves as seminar instructors and shared their own research areas, including homelessness, media studies, gender issues, and domestic violence. Terra, for example, shared her interest in religion and alternative medicine, explaining how even though she had been assigned the Habitat for Humanity placement, her lectures and discussions would likely include these topics as well as those related to housing and homelessness, etc. Accordingly, students interested in similar issues might find her section a good fit. However, it was also made clear to students that although each individual graduate student instructor would likely use examples from their own areas of interest, there would be some consistency in the seminars, as the topics covered would relate to lecture material from the primary instructor. The main purpose of these presentations was to inform students about the placements, but we also wanted to create excitement about the CSL opportunities being offered.

During the summer, we developed what we thought was a fair procedure for the assignment of students to seminar groups and CSL/media groups. After hearing the presentations by the community partners, CSL staff, and graduate student instructors, students were asked to submit a one to two paragraph rationale explaining their choice of the CSL or media option. This constituted their first graded assignment. If students were interested in doing community service-learning, they were asked to select their top two placement choices and explain their interest. Students who opted not to choose the CSL option were asked to indicate why they had selected the media option and were encouraged to think through their top two social issue topics based on the subject matter related to each CSL placement. This was a way to help direct students in their choice of a specific seminar group based on the group's community partner (i.e., if the student had an interest in issues relating to social and economic inequality, poverty, or homelessness, for example, they might choose the CSL seminar group that was partnered with Habitat for Humanity).

Two of the graduate student instructors, Terra and Greg, volunteered to review the students' responses and assign students to the respective seminars and CSL/media options. It was evident that some students preferred the CSL option because they could personally relate to the social issue; for example, one student's response mentioned his previous experience with homelessness and expressed a desire to support people in similar situations. He stated:

My second choice for tutorial placement is in the Habitat for Humanity group. Being a student, I understand what it means to have low income. I was also homeless for a month, which gave me incredible insight and respect for home owners and renters. Being a young adult, I also eventually want to purchase a home and with the current state of the housing market, home owning seems unachievable.

Even though the Habitat for Humanity placement was his second choice, his rationale 
positioned him as an ideal fit for that option. Other students interested in a CSL placement at REACH (an organization that supports crime prevention programs) stated their concern with crime and the increasing number of homicides in Edmonton. These students expressed their desire to learn about crime prevention and the difficulty marginalized individuals experience accessing resources. One student's rationale reads as follows:

My first choice of tutorial placement would be in the REACH Edmonton group. I currently live in downtown Edmonton, and witness the effects of crime every day. I support the REACH program in their efforts to improve community safety and awareness. The contrast to my previous residence in St. Albert is remarkable, as there was little to no crime.

Every effort was made to ensure students were given a fair chance on a first-come-first-serve basis to a CSL opportunity or the media option. CSL ended up being very popular; the limited number of CSL spots meant that not all students who requested a CSL placement were able to secure a spot and not all students who secured CSL spots did so with their desired organizations. We tried our best to accommodate students who did not receive one of their top two choices by assigning them another placement that addressed similar social issues. For instance, some students who selected Elizabeth Fry Society were moved into the REACH placement because the former placement filled up quickly, yet both dealt with crime. We recognize that this process may have disappointed a few students, but we tried to troubleshoot these issues to the best of our ability.

\section{Evaluating the Project}

We began this endeavor unsure of what to expect: How would undergraduate students respond to the CSL course component? How would the CSL and media components play out? How would we manage both the CSL and media components within the seminars? We were also unsure what to expect in terms of the impact the experience would have on graduate student instructors. The research component of the pilot project aimed to explore the impact of CSL on undergraduate and graduate students. Undergraduate students completed three surveys near the end of the term. ${ }^{3}$

Evaluating the graduate student experience and potential pedagogical learning throughout the course was also an important part of the evaluation component of the project and is the focus of this article. This evaluation was done on an ongoing informal basis, as well as through more formalized feedback at the end of the term. During our regular meetings throughout the term, graduate student instructors shared reflections on pedagogical and logistical experiences and lessons learned, addressing questions like: What worked in seminar this week? What did not work and why? What exercises are we considering for upcoming seminars? In addition

\footnotetext{
${ }^{3}$ The three surveys were: 1) the standard course evaluation with Likert scale questions and an optional feedback section provided to students in all campus courses; 2) a standard survey with open- and closed-ended questions administered by the CSL program in all CSL courses; and 3) a survey created by the primary instructor specifically to evaluate this course.
} 
to contributing to the discussion and sharing her ideas from previous years, the primary instructor took extensive notes at these meetings to analyze upon completion of the term. These meetings also functioned as an opportunity to vent and receive support. For example, some of the graduate student instructors expressed frustration with what they felt was a lack of formal training in CSL, as well as a lack of engagement from community partners prior to course commencement. We all struggled with trying to "seamlessly" integrate the experiences of CSL students with media students in seminars and lectures. The rapport built within our group (graduate student instructors and primary instructor) was such that the discussions were open, honest, sometimes heated, but always respectful. In addition to these ongoing meetings, we held a debrief session at the end of term with all six graduate student instructors, the primary instructor, and CSL staff. This allowed graduate students to share with CSL staff their experiences, including the frustrations and difficulties mentioned above, and to provide recommendations for future CSL projects.

Upon completion of the term, graduate student instructors were also asked to answer a series of open-ended evaluation questions, reflecting on their experience with the project, which were similar to the questions asked throughout the term: What worked? What did not? What would you do again? What would you change? ${ }^{4}$ The primary instructor then conducted a thematic analysis of the open-ended evaluation questions, and integrated her notes from the ongoing meetings throughout the term. She wrote a draft manuscript based on the analysis and shared it with the graduate student instructors for comments. Each gave detailed feedback on the draft report and a meeting was held to discuss the manuscript and findings. This evaluative component was a collaborative process that involved five of the six graduate students (one of the graduate students opted not to participate in the writing process because of career and life circumstances).

\section{Discussion of Main Themes}

Below, we discuss and reflect on some of the most significant themes that emerged from the graduate student instructors' feedback on the entire experience, focusing specifically on impacts and benefits for the graduate student instructors. ${ }^{5}$ Both challenges and positive outcomes are addressed.

\section{Formal training and practical classroom experience}

A major challenge the graduate student instructors encountered was that even though some had previous experience teaching seminars, this was their first exposure to CSL pedagogy as instructors. Although there is a relative paucity of research in this area, it seems clear that first time graduate student instructors in any setting - regardless of CSL components - tend to face a variety of challenges (Jungels, Brown, Stombler, \& Yasumoto, 2014). For example, graduate student instructors commonly receive minimal teacher training and must often

\footnotetext{
${ }^{4}$ See Appendix for a list of these questions.

5 To maintain anonymity of responses, we have chosen not to connect them to specific graduate student instructors.
} 
resort to mentoring one another informally by sharing tips, best practices, role expectations, and norms regarding course content and structure (Gardner \& Jones, 2011; Hunt, Mair, \& Atkinson, 2012). This lack of institutional support can increase the anxiety that many firsttime teachers experience - the anxiety that results from feeling unprepared, lacking confidence, having problems with student-teacher interactions, and experiencing an overall lack of formal support and guidance (Jungels et al., 2014; Smollin \& Arluke, 2014; Pelton, 2014). The stress posed by these challenges is exacerbated when combined with the additional uncertainty and responsibilities associated with CSL integration.

In the case of our course, some of these challenges were addressed by providing graduate student instructors with formal pedagogical training and exposure to the challenges and benefits of CSL in practice. As described above, CSL workshops were devised specifically for the graduate student instructors, the primary instructor conducted a workshop on constructing seminar syllabi, and a campus expert provided information on assignment and rubric creation.

In addition to the formal training, graduate student instructors were provided with the opportunity to practice teaching in seminars on a weekly basis, with the support of their fellow graduate student instructors and the primary instructor throughout the term. As one graduate student instructor stated, "This experience allowed me to hone my teaching skills." Another indicated that this course added "specific experiences" for a "teaching toolbox." In addition to gaining practical teaching experience that will be beneficial for future primary instructor responsibilities, graduate student instructors were able to witness firsthand the value of incorporating CSL into the course for undergraduate students (in seminar discussions), community partners (since the graduate student instructors liaised with community partners), and fellow instructors (during reflection). Graduate student instructors agreed that CSL is a valuable teaching tool, and as one instructor expressed, "Grounding academic knowledge in lived experience adds tools for students to evaluate, make sense of, and critique both." Another one of the instructors came to understand the value of the "philosophy of teaching around community engagement":

I learned that CSL helps break down the myth or idea of the University being this "ivory" tower. . . . I think bridging this gap between university and community is important to improve how both the institution and community generate knowledge or collaborate on a project to give students a hands-on experience to learning.

Nonetheless, we faced challenges that can accompany any course that integrates CSL. For example, while we sought to avoid the CSL/non-CSL distinction, deliberately choosing the label "media students" to stress students' unique contributions and avoid the negative connotations of "non-CSL," graduate student instructors reported struggling with trying to counteract this divisiveness throughout the term. They also reported difficulty linking media students' research with CSL students' experiences (as well as CSL students' experiences with course material). In an effort to facilitate exchange between the groups, one graduate student instructor encouraged media students to pair up with CSL students to peer-edit journal

Engaged Scholar Journal: Community-Engaged Research, Teaching, and Learning 
entries. Graduate student instructors also shared media reports that tied into course content during seminar discussions to engage students and attempt to draw connections between CSL experiences, media findings, and course material.

Arranging community placements for ninety students is daunting. We appreciate the stress this project placed on our institution's CSL office, as it was their first time integrating CSL into a large classroom. An issue that the graduate student instructors faced immediately, however, was the need for placements that would involve ongoing CSL participation. Although some placements had ongoing responsibilities for students, others did not. For example, two placements were "one-offs" (specific events rather than ongoing projects) that only involved students for a few days late in the term. It became clear to the graduate student instructors whose CSL students were assigned these placements that this structure was not conducive to the kind of steady discussion and sharing of experiences throughout the term that facilitates transformative learning. ${ }^{6}$ Graduate student instructors were required to navigate this challenge because CSL students needed to fulfill CSL commitments, as well as course requirements. In these cases, CSL students were not actually doing CSL until the last three weeks of the course. Since these students had no "material" to contribute to the seminars, the graduate student instructors were unable to help explicate connections between the course material and the "real world" of the placement (and thereby actually integrate CSL into their seminars). In addition, CSL students were required to complete their reflective assignments without the benefit of CSL experience to write about, and so they were encouraged, like the media students, to look to the media for assistance. CSL students complained that writing journal entries was difficult when very little CSL work was taking place, which became a huge concern. As one graduate student instructor explained, this "prompted some CSL students to voice their displeasure at the apparent inequity in workload." In fact, this tension endured throughout the course, for despite our best efforts to equalize the work done by CSL and media students, both groups expressed their frustration with a perceived inequality in workload; each group thought the other had it "easier" than they themselves did.

Another challenge arose in placements that did not actually involve community presence. For instance, students working with the REACH community partner were not required to visit a community site because the placement offered a lot of flexibility in terms of where the work was performed. As a result, for some students the service work was being performed alone in their homes on the internet for many hours. When reading their journal entries, the graduate student instructor could sense the students' isolation and how individualistic the work became, despite CSL's explicit focus on strengthening communities. Although working in isolation and outside the organization limited the type of critical reflections students could offer, the instructor encouraged the students to analyze their experiences in terms of a "sense of belonging" to society. Some students went beyond this suggestion to think through the implications of the resources they found on the internet; for example, some resources around

\footnotetext{
${ }^{6}$ In retrospect, this issue could have been addressed through course design by having students prepare for the "event" by doing research, preparing proposals, and getting feedback from community partners, thereby being "immersed" in the project even though they technically were not yet participating in the event.
} 
certain social issues, like bullying, were outdated or not available on the agency's website. One student connected these internet resources on bullying to his own personal experience as a victim of bullying. The graduate student instructors and their students were challenged to work together to deal constructively with the problems they faced.

Graduate student instructors also made an effort to discuss issues or challenges with CSL in the classroom setting. This allowed other students in the seminars to contribute to the rich discussions around community and the benefits of CSL, even if a particular student was not having an "ideal" CSL experience. Graduate student instructors also contacted community partners to discuss ways to ensure that students could still think through the course assignments in connection to their community service work.

Community service-learning partnership challenges, such as one-offs and isolation, required critical and reflexive thinking between graduate student instructors, undergraduate students, and community partners. As a result, they also offered learning opportunities for graduate student instructors, who modified teaching plans to accommodate the "messiness" of the CSL placements. We learned CSL (and teaching in general) requires flexibility and time compared to other types of teaching assistantships. However, graduate student instructors also received formal training and hands-on teaching experience and strategies for incorporating CSL, which will be beneficial when they are assigned primary teaching responsibilities in the future.

\section{Informal mechanisms of support}

Perhaps one of the most surprising findings was the development of informal mechanisms of support through the teaching assignment, which buttressed the formal support and training. As previously mentioned, our group meetings and the relationships we formed were major sources of pedagogical, professional, and emotional support. Graduate student instructors brought forward student concerns regarding CSL experiences at the group meetings. The team listened to the problems, shared strategies from their own seminars, and offered suggestions. Our strong, collaborative "teaching community network" (Hunt, Mair, \& Atkinson, 2012, p. 199) contributed significantly to the project and the experiences of the graduate student instructors.

The significance of collaboration, not only in the planning stages of the class, but also in ongoing problem-solving, was central in graduate student instructors' feedback. Most graduate student instructors commented on the benefits of the regular meetings to workshop ideas and support each other in the navigation of challenges. It is worth noting that the weekly meetings were not compulsory, yet most, if not all graduate student instructors attended them faithfully, whether they personally required the group support or not. They appreciated that if they personally did not require support that week, perhaps their colleagues might. Interestingly, graduate student instructors also met on their own (in pairs over coffee, for example, to discuss group exercises or issues they had with evaluating student work) outside of the scheduled group meetings. They also consulted and met with the primary instructor as needed. Email communication occurred regularly between graduate student instructors and 
the primary instructor throughout the term. As one graduate student instructor explained,

I loved the team work we had going on throughout the term. I knew I could always depend on the other graduate student instructors for support and [the primary instructor]. [....] Teaching is definitely improved by the cohort effect because it gives you an opportunity to guide each other to share what works for you or [what] does not and creates this space for learning [whereby] you feel connected with the course/ other [graduate student instructors].

Graduate student instructors not only found the group support rewarding, they also felt it may have improved the flow and success of the course. As one of the graduate student instructors reflects, "We may have made fewer mistakes because we learned from each other." In this way, formal training, practical classroom experience, and emotional, educational, and professional support came together.

\section{Conclusion}

The primary instructor who initiated this pilot project had two goals: 1) to introduce undergraduate students to CSL and the sociological perspective early in their academic careers; and 2) to provide graduate student instructors with professional development and experience with CSL as pedagogical practice. Ultimately, we recognized that the course had a multifaceted impact on its instructors. Graduate student instructors had transformative teaching experiences through formal and informal support mechanisms that developed as the course unfolded (Jungels et al., 2014).

The course provided graduate student instructors with unique professional training that included real classroom teaching and an innovative pedagogical approach. We learned that incorporating CSL into a large introductory sociology class is feasible, but in our case it required six graduate student instructors, a primary instructor committed to mentoring the graduate student instructors, and CSL program and department support. A research grant to experiment with this course format made this project possible. The formal supports, including training from CSL staff and a writing expert on campus, were critical to executing the course and standardizing seminar groups. However, equally important (and unexpected on our part) was the informal support system that emerged. Meetings throughout the term enabled graduate student instructors to reflect collectively on experiences, debrief after seminars, share ideas, and brainstorm solutions to the "messiness" of incorporating CSL into a large introductory sociology class.

One of the goals of this article is to privilege the experiences of the graduate student instructors in this pilot project. Graduate student voices regarding teaching experience and professional development are relatively scarce in teaching literature. Also uncommon are faculty experiences with integrating CSL into their courses, especially regarding the "messiness" that accompanies this type of pedagogical approach with multiple partners (graduate students, 
undergraduates, community partners, and CSL program staff). ${ }^{7}$ Most CSL literature focuses on students' experiences with the pedagogical practice. Faculty considering integrating CSL into a class and/or involving graduate student instructors may find our reflections helpful. Finally, little research exists on the incorporation of CSL into large sociology classrooms.

Administrators, instructors, and graduate student instructors face growing pressures and demands due to increased student enrolment, budgetary constraints, and larger class sizes, all of which limit the potential attention to individual students (Crull \& Collins, 2004; Hill et al., 2010). Graduate student instructors face growing expectations and responsibilities due to the rising demand for them to be the primary instructors of undergraduate (particularly introductory) courses (Gardner \& Jones, 2011). Consequently, graduate student instructors increasingly shape the nature and quality of undergraduate education (Gardner \& Jones, 2011), a fact which emphasizes the necessity of pedagogical training. In response to this necessity, Jungels and colleagues (2014) propose the unique position of a Teaching Associate, who is tasked with providing formal and informal mentorship and support to graduate students facing teaching duties for the first time. This paper provides another option for graduate student instructor training, which includes formal teacher training and a transformative pedagogical approach.

CSL in a large introductory sociology course is a worthwhile endeavour that instructors may find more satisfying over time, especially when pedagogical gains outweigh the challenges. As each placement and partnership was different and unique, we were unable to predict the challenges that would arise, and we learned that there is no one way to tackle both anticipated and unexpected challenges. Rather, we remind instructors and community partners that CSL will in fact bring forward obstacles or struggles to work through, as well as some frustrations, but that the experience does create a transformed learning space for all involved. Providing opportunities to discuss CSL as well as the messiness around it (Himley, 2004) and encouraging graduate student instructor involvement in courses with such components can effectively engage graduate students and faculty in service work (O’Meara, 2008). We hope that CSL will become more prominent in the Canadian academic landscape. In fact, we repeated the effort

\footnotetext{
${ }^{7}$ From the perspective of the primary instructor, there are several things I learned from the experience that would influence the way I approach this type of course in the future. I think at the "front end" of course development, having graduate student instructors have a say in who their community partners are is very important - in fact, critical— to the success of the experience. I would go so far as to say that community partners should be actively involved in the creation of the seminar syllabi in order to ensure as much as a possible a smooth linkage between what CSL students experience in the community and the classroom. To this end, I would also ask CSL staff for more formal training for graduate student instructors and primary instructors in methods for integrating CSL into the course and ensuring equity in work load experience for CSL and "non-CSL" students. I would also do more in terms of assisting graduate student instructors with lecture development (i.e., perhaps hold a workshop session on developing a student-centered lecture) (Troop, Wallar, \& Aspenlieder, 2015), conduct more classroom visits in order to provide feedback to graduate student instructors (Parker, Ashe, Boersma, Hicks, \& Bennett, 2015), and do more to bring CSL and media student experiences into the larger lecture. From the primary instructor's perspective, what was interesting and quite telling was, at the end of the course, all six graduate student instructors were keen to "try it again" with the same course the following fall. It is significant that despite the challenges, there was a sense among us all that we were not ready to give up on integrating CSL into a large sociology classroom after this one experience.
} 
at teaching CSL in a large introductory sociology class the year following this pilot project and look forward to reporting on that experience.

\section{Acknowledgements}

This pilot project was made possible thanks to generous funding from the University of Alberta's Teaching and Learning Enhancement Fund, the Department of Sociology, and inkind support from the Community Service-Learning program at the University of Alberta. Graduate student instructor involvement in the evaluation component of the project received institutional ethics approval.

\section{About the Authors}

Wendy Aujla is a Doctoral Candidate in sociology at the University of Alberta. She served as an advisory board member for the Community Service-Learning Program at the U of A (20122016). Wendy's teaching and research interests include community, gender, race, ethnicity, and family with specific attention to violence against women.

Laura Aylsworth is a $\mathrm{PhD}$ Candidate in the Department of Sociology at the University of Alberta. Her research specializes in gender, social inequality, and criminalization through a feminist lens. Her recent work examines agency and identity in sex work.

Greg Eklics completed an MA in criminology and sociology at the University of Windsor and has taught post-secondary courses both in sociology and criminology. He is currently the criminology program advisor at the University of Alberta.

Jana Grekul (corresponding author) is associate professor in sociology and director of the BA (Criminology) program at the University of Alberta. Her research interests include street and prison gangs, women's incarceration and reintegration, and experiential learning. She has also conducted research on the professional development of graduate students, including teaching mentorship. Email: jgrekul@ualberta.ca

Terra Manca is a postdoctoral fellow at Dalhousie University. Her recent research and articles address healthcare providers narratives about vaccine efficacy, medical knowledge, and medical 
uncertainties. In addition, she has published on topics including Scientology and health, Christian Scientists' healthcare practices, family life in strict religions, and medical education.

Ashley Elaine York completed her PhD at the University of Alberta in 2016. Her areas of research interest include Media, Gender, Work and Organizations. Ashley Elaine also held a Corus Entertainment PhD Fellowship in Television Studies.

\section{References}

Brooks, J. M. (1997). Sociology and virtual teaching and learning. Teaching Sociology, 27, 1-14.

Butin, D. W. (2007). Focusing our aim: Strengthening faculty commitment to community engagement. Change, November/December, 34-39.

Chesler, M. A., Ford, K. A., Galura, J. A., \& Charbeneau, J. M. (2006). Peer facilitators as border crossers in community service learning." Teaching Sociology, 34(4), 341-356.

Crull, S. R., \& Collins, S. M. (2004). Adapting traditions: Teaching research methods in a large class aetting. Teaching Sociology, 32(2), 206- 212.

Dorow, S., Wolfe, R., Taylor, A., Trueblood, L., \& Goebel, M. (2013). 'The stranger' in CSL pedagogy and research: Learning in, through, and for CSL as anti-foundational practice. In L. Shultz and T. Kajner (Eds), Engaged Scholarship: The Politics of Engagement and Disengagement (pp. 6988). Rotterdam, The Netherlands: Sense Publishers.

Gardner, G. E. \& Jones, M. G. (2011). Pedagogical preparation of the science graduate teaching assistant: Challenges and implications. Sciences Educator, 20(2), 31-41.

Hill, S. D., Loney, R. K., \& Reid, H. (2010). Notes from the field: Brokering service learning between a rural community and large undergraduate class: Insights from a case study. Journal of Community Practice, 18(2-3), 396-412.

Himley, M. (2004). Facing (up to) 'the stranger' in community service learning. College Composition and Communication, 55(3), 416-438.

Hinck, S. S., \& Brandell, M. E. (2000). The relationship between institutional support and campus acceptance of academic service learning. The American Behavioral Scientist, 43(5), 868-882. Hironimus-Wendt, R. J., \& Wallace, L. E. (2009). The sociological imagination and social responsibility. Teaching Sociology, 37(1), 76-88.

Hondagneu-Sotelo, P., \& Raskoff, S. (1994). Community service-learning: Promises and problems. Teaching Sociology, 22 (3), 248-254.

Hou, S. I. (2010). Developing a faculty inventory measuring perceived service-learning benefits and barriers. Michigan Journal of Community Service Learning, 16(2), 78-89.

Hunt, A. N., Mair, C. A., \& Atkinson, M. P. (2012). Teaching community networks: A case study of informal social support and information sharing among sociology graduate students. Teaching Sociology, 40(3), 198-214.

Jakubowski, L. M., \& Burman, P. (2004). Teaching community development: A case study in community. Teaching Sociology, 32(2), 160-176.

Jay, G. (2008). Service learning, multiculturalism, and the pedagogies of difference. Pedagogy, 8(2), 255281.

Engaged Scholar Journal: Community-Engaged Research, Teaching, and Learning 
Jungels, A. M., Brown, M. A., Stombler, M., \& Yasumoto, S. (2014). Teaching associates: Bridging informal and formal mechanisms of support for graduate student instructors. Teaching Sociology, 42(3), 220-230.

Lena, H. F. (1995). How can Sociology contribute to integrating service learning in academic curricula? The American Sociologist, 26(4), 107-117.

Mezirow, J. (2000). Learning to think like an adult: Core concepts of transformation theory. In J. Meziow (Ed.), Learning as transformation: Critical perspectives on a theory in progress (pp. 3-34). New York, NY: John Wiley.

McGonigal, K. (2005). Teaching for transformation: From learning theory to teaching strategies. Speaking of Teaching, 14(2), 5pgs.

Miller, J. E., \& Groccia, J. E. (1997). Are four heads better than one? A comparison of cooperative and traditional teaching formats in an introductory Biology course. Innovative Higher Education, 21(4), 253-273.

Mooney, L. A., \& Edwards, B. (2001). Experiential learning in Sociology: Service learning and other community-based learning initiatives. Teaching Sociology, 29(2), 181-194.

O'Meara, K. (2008). Graduate education and community engagement. New Directions for Teaching and Learning, 113, 27-42.

O’Meara, K., \& Niehaus, E. (2009). Service-learning is...How faculty explain their practice. Michigan Journal of Community Service Learning, 16(1), 17-32.

Parker, M A., Ashe, D., Boersma, J., Hicks, R., \& Bennett, V.. (2015). Good teaching starts here: Applied learning at the Graduate Teaching Assistant Institute. Canadian Journal of Higher Education, 45(3), 84-110.

Pelton, J. A. (2014). Assessing graduate teacher training programs: Can a teaching seminar reduce anxiety and increase confidence? Teaching Sociology, 42(1), 40-49.

Potter, S. J., Caffrey, E. M. \& Plante, E. G. (2003). Integrating service learning into the research methods course. Teaching Sociology, 31(1), 38-48.

Pribbenow, D. A. (2005). The impact of service-learning pedagogy on faculty teaching and learning. Michigan Journal of Community Service Learning, 11(2), 25-38.

Smollin, L. M. \& Arluke, A. (2014). Rites of pedagogical passage: How graduate student instructors negotiate the challenges of first time teaching. Teaching Sociology, 42(1), 28-39. Troop, M., Wallar, L., \& Aspenlieder, E. (2015). Developing graduate students' self-efficacy with learnercentred lecturing. Canadian Journal of Higher Education, 45(3), 15-33.

University of Alberta. (n.d.). Mission, vision, values.

Westheimer, J., \& Kahne, J. (2004). What kind of citizen? The politics of educating for democracy. American Educational Research Journal, 41(2), 237-269. 


\section{Appendix: Graduate Instructor Evaluation Questions}

Were you familiar with CSL before teaching this course? What have you learned about CSL, University-community partnerships?

Is there value in incorporating CSL into classes? What have you learned from this experience?

How did you relate to the planning process for this course?

Can you please reflect on the teaching process itself - did you experience difficulties with integrating CSL into the seminar? How did you deal with these difficulties? Did you experience successes in doing so? Can you describe these successes?

Have you thought differently about your own teaching as a result of this experience?

Please reflect on whether teaching is improved by the 'cohort effect' (team teaching).

How useful (if at all) were the meetings during the summer, meetings with Roger, meetings throughout the term?

How can we improve our integration of CSL into the course?

What did you think of the assignments? What could we do differently to improve the experience for CSL and Media students?

Please reflect on what you did to make the 'connections' between CSL/Media and course material happen. What specific techniques/exercises did you use to try and assist students to make these connections?

Can you describe any specific instances of how CSL helped student learning? (any situations where CSL helped concepts come alive for students?)

How would you improve the seminars if you were to teach this course again?

Do you have suggestions for improving the seminars for instructors? For undergraduates?

Any thoughts on integrating CSL into the larger classroom (lecture)?

Would you consider incorporating CSL into a future course you might teach?

What worked for you/us this term?

What didn't work for you/us this term?

What advice would you give future instructors of this type of a course?

What advice would you give future seminar instructors/graduate students involved in this format/type of course/?

Do you have additional comments you would like to share?

Engaged Scholar Journal: Community-Engaged Research, Teaching, and Learning 